\title{
Model Space Time Autoregressive (STAR) Orde 1 Dan Penerapannya Pada Prediksi Harga Beras Di Kota Manado, Tomohon Dan Kabupaten Minahasa Utara
}

\author{
${ }^{1}$ Rahmadania Paita, ${ }^{2}$ Nelson Nainggolan, ${ }^{3}$ Yohanes A.R. Langi \\ ${ }^{1}$ Program Studi Matematika, F-MIPA, UNSRAT, rahmdaniapaita@ymail.com \\ ${ }^{2}$ Program Studi Matematika, F-MIPA, UNSRAT, bapaivana@yahoo.co.id \\ ${ }^{3}$ Program Studi Mate matika, F-MIPA, UNSRAT, yarlangi@ gmail.com
}

\begin{abstract}
In this research the model is described by using the Space Time Autoregressive (STAR) Model Order 1 of the price of rice in Manado, Tomohon and North Minahasa regency consist of Membramo and Superwin rice. The data were used monthly data from January 2008 to September 2013. Estimating parameter results of STAR model order 1 for Superwin and Membramo are given with parameters -0.182, 0.146, - 0.068 and 0.102. Prediction results were obtained for the periods of October, November and December of 2013 in Manado Location which Superwin Rice has the same type of rice Rp. 9,500 and Membramo type is Rp. 9,000. For To mohon predictions were obtained for the periods of October, November and December of 2013 with Superwin Rice is the same type of Rp. 9,000 and Membramo type is Rp. 8,700 while for North Minahasa regency prediction results were obtained for the periods of October, November and December of 2013 with Superwin Rice is the same type of rice Rp. 9,000 and Membramo type Rp. 8,800.
\end{abstract}

Keywords : rice, space-time, STAR models, time series

\begin{abstract}
Abstrak
Dalam penelitian ini diuraikan model Space Time Autoregressive (STAR) Orde 1 dari harga beras di Kota Manado, Tomohon dan Kabupaten Minahasa Utara yang terdiri dari beras Superwin dan Membramo. Data yang digunakan adalah data bulanan periode Januari 2008 sampai September 2013. Hasil penaksiran parameter model STAR orde-1 untuk superwin dan me mbramo memberikan nilai taksiran parameter -0.182 , $0.146,-0.068$ dan 0.102. Hasil Prediksi yang diperoleh untuk periode bulan Oktober, November dan Desember tahun 2013 di Lokasi Manado dengan Jenis Beras Superwin adalah sama yakni Rp. 9.500 dan jenis Membramo adalah Rp. 9.000. Untuk Kota Tomohon prediksi yang diperoleh untuk periode bulan Oktober, November dan Desember tahun 2013 dengan jen is beras Superwin adalah sama yakni Rp. 9.000 dan Jenis Membramo adalah Rp. 8.700 sedangkan untuk Kabupaten Minahasa Utara hasil prediksi yang diperoleh untuk periode bulan Oktober, Nove mber dan Desember tahun 2013 dengan jenis beras Superwin adalah sama yakni Rp. 9.000 dan jenis Membramo Rp. 8.800 .
\end{abstract}

Kata kunci : beras, model STAR, space time, time series.

\section{Pendahuluan}

Pangan merupakan komoditas strategis dan bahkan sering dikaitkan dengan aspek politis di berbagai negara termasuk Indonesia. Hal ini disebabkan karena pangan merupakan kebutuhan dasar manusia untuk mempertahankan hidup. Harga dan kaitannya dengan peningkatan pendapatan dan kesejahteraan petani merupakan salah satu elemen penting dalam ekonomi pangan [7].

Salah satu komoditi pangan yang banyak dikonsumsi sebagian besar warga Sulawesi Utara adalah beras. Pada umumnya harga beras di Sulawesi Utara dari waktu ke waktu mengalami kenaikan, sehingga data harga beras menujukkan pola yang tidak stasioner [8].

Salah satu model da lam statistika yang dapat menggabungkan unsur ketergantungan waktu dan lokasi pada suatu data deret waktu peubah ganda adalah model ruang waktu. Model ruang waktu (space time) ini pertama kali diperkenalkan oleh Pfeifer dan Deutsch [6]. Model ruang waktu yang sering digunakan adalah STAR (Space Time Autoregressive) dan GSTAR (Generalized Space Time Autoregressive). Pada model STAR lebih sesuai untuk lokasi dengan karakteristik homogen, karena model tersebut mengasumsikan parameter regresi diri dan parameter ruang waktu bernilai sama untuk semua lokasi. Model STAR merupakan model time series autoregresi dari Box-Jenkins yang dikembangkan di beberapa lokasi secara simultan [5]. 


\section{Model Space Time Autoregressive (STAR)}

Perkembangan mengenai analisis deret waktu memunculkan pemikiran bahwa beberapa data dari suatu kejadian tidak hanya mempunyai keterikatan dari kejadian-kejadian pada waktu sebelumnya tetapi juga mempunyai keterikatan dengan lokasi yang disebut dengan Space Time. Model Space Time adalah suatu model yang menggabungkan faktor waktu dan lokasi pada data deret waktu multivariat yang pertama kali diperkenalkan oleh Pfeifer dan Deutsch [5]. Salah satu pendekatan utama untuk menyelesaikan data deret waktu dan lokasi adalah model Space Time Autoregressive (STAR) dan Generalized Space Time Autoregressive (GSTAR).

Dalam kehidupan sehari-hari kita sering berhadapan dengan data time series dan analis is time series yang sudah kita kenal adalah Box-Jenkins yang dikembangkan sejak 1962. Selain data time series kita juga berhadapan dengan data yang bergantung dengan lokasi yang disebut data spasial [3].

Dengan menggunakan model Autoregressive (AR), maka [2] mengusulkan model STAR. Model ini menganggap kombinasi linier dari pengamatan sekarang merupakan kombinasi linier dari pengamatan masa lalu terboboti dan galat sekarang [3], ditulis:

dimana :

$$
Z(t)=\sum_{k=1}^{p} \sum_{l=0}^{\lambda_{k}} \phi_{k l} \boldsymbol{W}^{(l)} \mathbf{Z}(t-k)+\boldsymbol{e}(t)
$$

$Z(t)=\left(Z_{1}(t), \ldots, Z_{N}(t)\right)^{\prime} \quad:$ Vektor pengamatan di $N$ lokasi dengan $E[Z(t)]=0$

$\phi_{k l}$

$\boldsymbol{W}^{(l)}$

: Parameter autoregresif pada lag waktu $k$ dan lag spasial $l$

$\boldsymbol{e}(t)=\left(e_{1}(t), \ldots, e_{N}(t)\right)^{\prime} \quad:$ Menyatakan vektor galat pada saat $t$, $\varepsilon_{\sim}^{i i d} N$ dengan rataan 0 dan kovariansi konstan.

Model STAR (1;1) untuk 3 lokasi, dinyatakan sebagai berikut :

$$
z_{(3 \times 1)}(t)=\phi_{10} z_{(3 \times 1)}(t-1)+\phi_{11} W_{(3 \times 3)} z_{(3 \times 1)}(t)+e(t)
$$

dimana : $\quad e(t)^{i i d} \sim N\left(0, \sigma^{2} I_{3}\right)$

Dalam bentuk matriks, persamaannya dapat dituliskan sebagai berikut :

$$
\left(\begin{array}{l}
z_{1}(t) \\
z_{2}(t) \\
z_{3}(t)
\end{array}\right)=\phi_{10}\left(\begin{array}{l}
z_{1}(t-1) \\
z_{2}(t-1) \\
z_{3}(t-1)
\end{array}\right)+\phi_{11}\left(\begin{array}{ccc}
0 & w_{12} & w_{13} \\
w_{21} & 0 & w_{23} \\
w_{31} & w_{32} & 0
\end{array}\right)\left(\begin{array}{l}
z_{1}(t-1) \\
z_{2}(t-1) \\
z_{3}(t-1)
\end{array}\right)+\left(\begin{array}{l}
e_{1}(t) \\
e_{2}(t) \\
e_{3}(t)
\end{array}\right)
$$

Dengan perhitungan sebagai berikut :

$$
\begin{aligned}
& z_{1}(t)=\phi_{10} z_{1}(t-1)+\phi_{11}\left(w_{12} z_{2}(t-1)+w_{13} z_{3}(t-1)\right)+e_{1}(t) \\
& z_{2}(t)=\phi_{10} z_{2}(t-1)+\phi_{11}\left(w_{21} z_{1}(t-1)+w_{23} z_{3}(t-1)\right)+e_{2}(t) \\
& z_{3}(t)=\phi_{10} z_{3}(t-1)+\phi_{11}\left(w_{31} z_{1}(t-1)+w_{32} z_{2}(t-1)\right)+e_{3}(t)
\end{aligned}
$$

\section{Metode Penelitian}

\section{a) Data Penelitian}

Dalam penelitian ini data yang digunakan adalah data sekunder. Data berupa data kuantitatif harga bulanan beras sebanyak 69 data di setiap lokasi yakni Kota Manado, Kota Tomohon dan Kabupaten Minahasa Utara (Minut) dengan data harga beras periode bulan Januari 2008 sampai dengan bulan September 2013 dimana data yang diperoleh dari Dinas Perindustrian dan Perdagangan (DISPERINDAG) di masing-masing Kabupaten/Kota dan juga dari Badan Urusan Logistik Divisi Regional (BULOG DIVRE) Sulawesi Utara dan Gorontalo.

\section{b) Prosedur Penelitian}

Adapun prosedur yang dilakukan dalam penelitian ini adalah :

1. Pemeriksaan Kestasioneran

2. Identifikasi model 
3. Menentukan Matriks Bobot

4. Estimasi Parameter

5. Uji Diagnostik

6. Model Space Time

7. Menghitung Prediksi Harga.

\section{Hasil Dan Pembahasan}

\subsection{Harga Bulanan Beras Superwin dan Membramo di Kota Manado, Tomohon dan Kabupaten Minahasa Utara}

Eksplorasi data harga beras bulanan superwin dan membramo periode bulan Januari 2008 sampai dengan September 2013 sebanyak 69 data di 3 lokasi yakni Kota Manado, Tomohon dan Kabupaten Minahasa Utara dapat dilihat pada Gambar 1 dan Gambar 2.

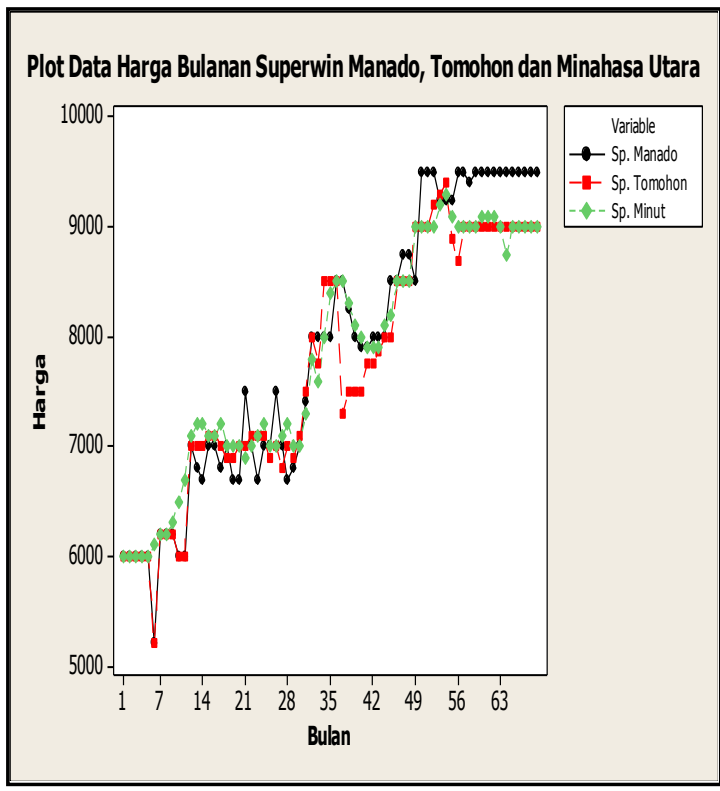

Gambar 1. Plot Data Harga Bulanan Superwin

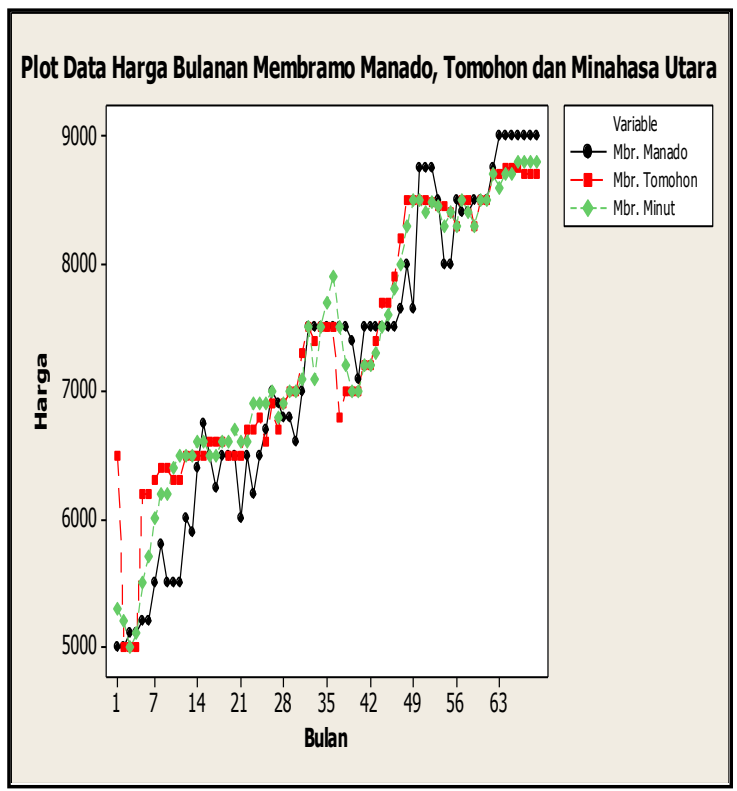

Gambar 2. Plot Data Harga Bulanan Membramo

Berdasarkan plot diatas terlihat bahwa grafik bergerak naik artinya data yang ada belum stasioner dalam rata-rata karena data bergerak mengikuti perubahan waktu.

Melalui analis is ACF PACF dan differencing diperoleh hasil bahwa data tersebut bersifat stasioner dengan nilai $\mathrm{d}=1$.

\subsection{Penentuan Model STAR Data Harga Bulanan Beras Superwin dan Membramo di Kota Manado, Tomohon dan Kabupaten Minahas a Utara}

Dari hasil penentuan identifikasi model diperoleh model STAR dengan parameter untuk beras superwin yakni diperoleh $\hat{b}_{1}=-0.186$ dan $\hat{b}_{2}=0.146$ dan beras membramo diperoleh yaitu $\hat{b}_{1}=-0.068$ dan $\hat{b}_{2}=0.102$.

Model STAR data harga beras superwin dan Membramo di 3 lokasi adalah sebagai berikut:

1. Model STAR Data Harga Beras Superwin di 3 lokasi :

$$
\begin{aligned}
\hat{Z}_{1}(t)= & Z_{1}(t-1)-0.186 Z_{1}(t-1)+0.186 Z_{1}(t-2)+0.146\left(0 . 5 \left(Z_{2}(t-1)-\right.\right. \\
& \left.\left.Z_{2}(t-2)\right)\right)+0.146\left(0.5\left(Z_{3}(t-1)-Z_{3}(t-2)\right)\right)
\end{aligned}
$$




$$
\begin{aligned}
\hat{Z}_{2}(t)= & Z_{2}(t-1)-0.186 Z_{2}(t-1)+0.186 Z_{2}(t-2)+0.146\left(0 . 5 \left(Z_{1}(t-1)-\right.\right. \\
& \left.\left.Z_{1}(t-2)\right)\right)+0.146\left(0.5\left(Z_{3}(t-1)-Z_{3}(t-2)\right)\right) \\
\hat{Z}_{3}(t)= & Z_{3}(t-1)-0.186 Z_{3}(t-1)+0.186 Z_{3}(t-2)+0.146\left(0 . 5 \left(Z_{1}(t-1)-\right.\right. \\
& \left.\left.Z_{1}(t-2)\right)\right)+0.146\left(0.5\left(Z_{2}(t-1)-Z_{2}(t-2)\right)\right)
\end{aligned}
$$

2. Model STAR Data Harga Beras Membramo di 3 lokasi :

$$
\begin{aligned}
\hat{Z}_{1}(t)= & Z_{1}(t-1)-0.068 Z_{1}(t-1)+0.068 Z_{1}(t-2)+0.102\left(0 . 5 \left(Z_{2}(t-1)-\right.\right. \\
& \left.\left.Z_{2}(t-2)\right)\right)+0.102\left(0.5\left(Z_{3}(t-1)-Z_{3}(t-2)\right)\right) \\
\hat{Z}_{2}(t)= & Z_{2}(t-1)-0.068 Z_{2}(t-1)+0.068 Z_{2}(t-2)+0.102\left(0 . 5 \left(Z_{1}(t-1)-\right.\right. \\
& \left.\left.Z_{1}(t-2)\right)\right)+0.102\left(0.5\left(Z_{3}(t-1)-Z_{3}(t-2)\right)\right) \\
\hat{Z}_{3}(t)= & Z_{3}(t-1)-0.068 Z_{3}(t-1)+0.068 Z_{3}(t-2)+0.102\left(0 . 5 \left(Z_{1}(t-1)-\right.\right. \\
& \left.\left.Z_{1}(t-2)\right)\right)+0.102\left(0.5\left(Z_{2}(t-1)-Z_{2}(t-2)\right)\right)
\end{aligned}
$$

Berdasarkan hasil yang ada yang diperoleh maka grafik prediksi untuk jenis beras Superwin dan Membramo dapat dilihat di gambar berikut :

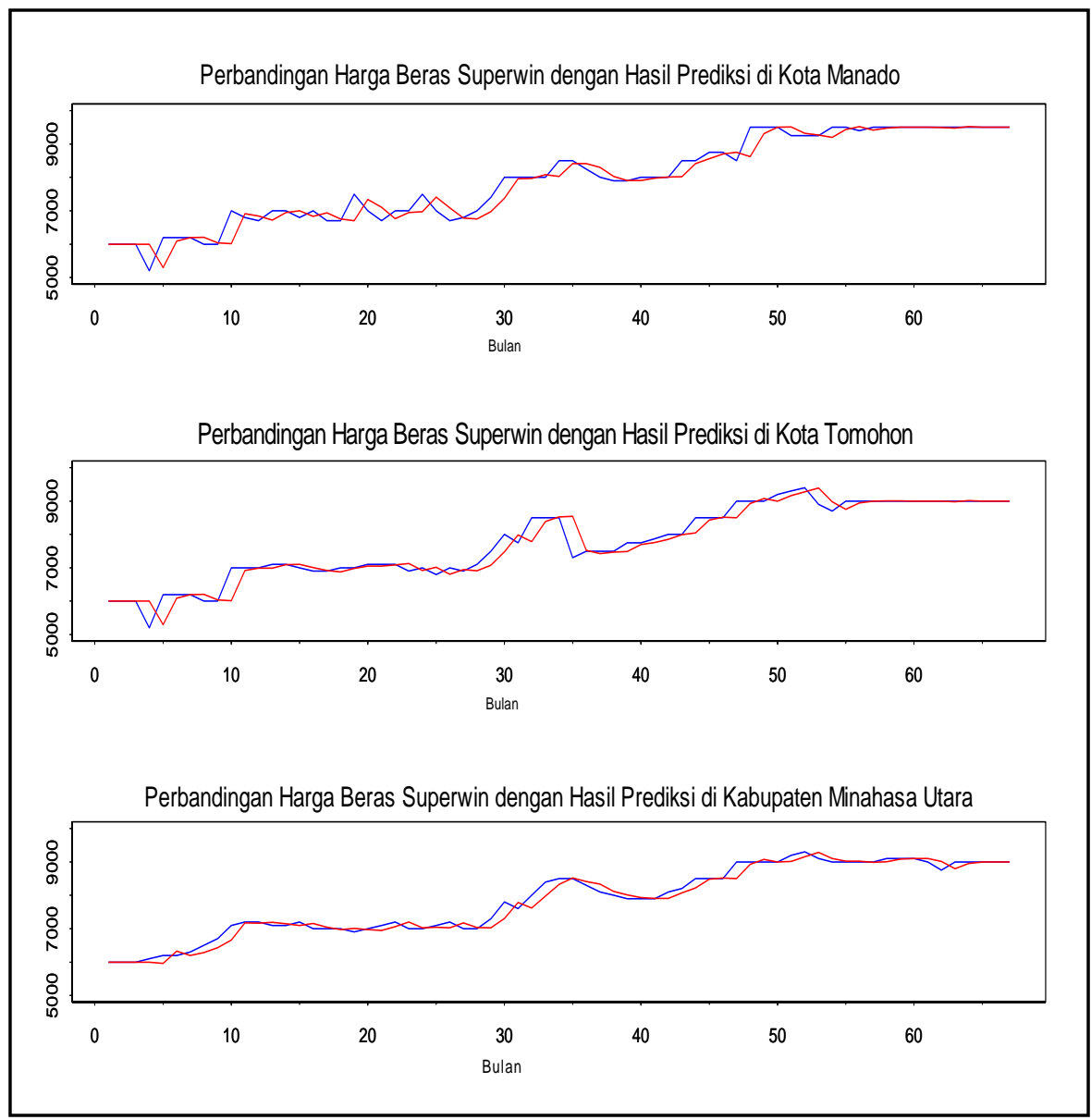

Gambar 3. Perbandingan Data Harga Bulanan Beras Superwin yang sebenarnya dibandingkan dengan Data Harga Beras Prediksi di Kota Manado, Tomohon dan Kabupaten Minahasa Utara 


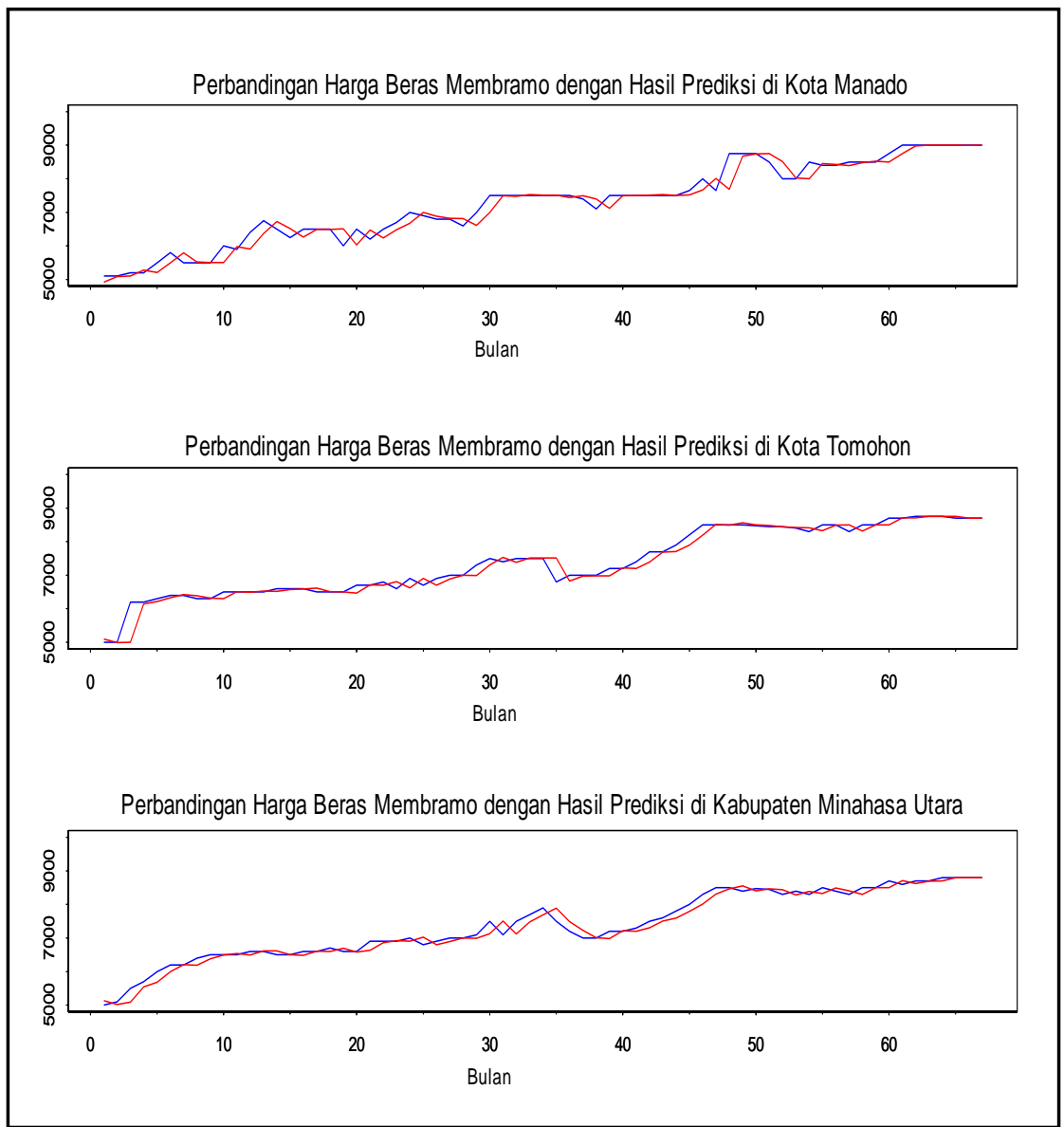

Gambar 4. Perbandingan Data Harga Bulanan Beras Membramo yang sebenarnya dibandingkan dengan Data Harga Beras Prediksi di Kota Manado, Tomohon dan Kabupaten Minahasa Utara

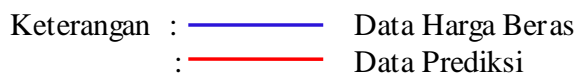

\subsection{Pre diksi Data Harga Bulanan Beras Superwin dan Membramo Pada Bulan Oktober 2013 sampai dengan Desember 2013}

Tabel 1. Prediksi Data Harga Super win di 3 Lokasi

\begin{tabular}{|c|c|c|c|c|}
\hline No & $\begin{array}{c}\text { Bulan/ } \\
\text { Tahun }\end{array}$ & Manado & Tomohon & Minut \\
\hline 1 & Okt-13 & 9.500 & 9.000 & 9.000 \\
\hline 2 & Nov-13 & 9.500 & 9.000 & 9.000 \\
\hline 3 & Des-13 & 9.500 & 9.000 & 9.000 \\
\hline
\end{tabular}

Tabel 2. Prediksi Data Harga Membramo di 3 Lokasi

\begin{tabular}{|c|c|c|c|c|}
\hline No & $\begin{array}{c}\text { Bulan/ } \\
\text { Tahun }\end{array}$ & Manado & Tomohon & Minut \\
\hline 1 & Okt-13 & 9.000 & 8.700 & 8.800 \\
\hline 2 & Nov-13 & 9.000 & 8.700 & 8.800 \\
\hline 3 & Des-13 & 9.000 & 8.700 & 8.800 \\
\hline
\end{tabular}




\section{Kesimpulan}

Hasil Prediksi yang diperoleh untuk periode Bulan Oktober, November dan Desember tahun 2013 di Lokasi Manado dengan Jenis Beras Superwin adalah sama yakni Rp. 9.500 dan Jenis Membramo adalah Rp. 9.000. Untuk Kota Tomohon prediksi yang diperoleh untuk periode Bulan Oktober, November dan Desember tahun 2013 dengan Jenis Beras Superwin adalah sama yakni Rp. 9.000 dan Jenis Membramo adalah Rp. 8.700 sedangkan untuk Kabupaten Minahasa Utara hasil prediksi yang diperoleh untuk periode Bulan Oktober, November dan Desember tahun 2013 dengan Jenis Beras Superwin adalah sama yakni Rp. 9.000 dan Jenis Membramo Rp. 8.800.

\section{Daftar Pus taka/Pus taka Acuan}

[1] Box, G.E.P., and Jenkins, G.M. 1976. Time Series Analysis: Forecasting and Control. Rev Edition. Holden Day Inc. San Fransisco.

[2] Cliff, A. D., and J. K. Ord. 1975. Space-Time Modelling with An Application to Regional Forecasting. Transactions of The Institute of British Geographie. Technische Universiteit Delft. $66: 119-128$,

[3] Nainggolan, N. 2011. Pengembangan Model GSTAR dengan Galat ARCH dan Penerapannya pada Inflasi. [disertasi] UNPAD, Bandung.

[4] Nuraini, B. 2002. Pemodelan Kurva Produksi Minyak Bumi Menggunakan Model Generalisasi STAR. Disampaikan pada Seminar Nasional Statistika. Prosiding Forum Statistika dan Ko mputasi; Institut Pertanian Bogor, Bogor, 28 September 2002.

[5] Pfeifer, P.E., dan Deutsch, S.J. 1980. A Three Stage Iterative Procedure for Space-Time Modelling. School of Industrial and System Engineering Georgia Institute of Technology Atlanta. Technometric. 22(1): 35-47.

[6] Rachman, S. P. H. 2013. Metode Analisis Harga Pangan. Pusat Analisis Sosial Ekonomi dan Kebijakan Pertanian. Bogor http://ketapang.deliserdangkab.go.id/2013/02/26/metode-analisis-harga-pangan.html [30 Mei 2013]

[8] Wuwung, V. 2012. Prediksi Harga Beras Sultan dan Membramo di Kota Manado dengan Menggunakan Model ARIMA [skripsi]. FMIPA UNSRAT. Manado. 